\title{
THE
}

\section{Understanding maternal intentions to engage in home visiting programs}

\author{
Karen McCurdy \\ University of Rhode Island, kmccurdy@uri.edu \\ Deborah Daro \\ Elizabeth Anisfeld \\ Aphra Katzev \\ Ann Keim
}

See next page for additional authors

Follow this and additional works at: https://digitalcommons.uri.edu/hdf_facpubs

This is a pre-publication author manuscript of the final, published article.

Creative Commons License

\section{cc) (i) $\ominus$}

This work is licensed under a Creative Commons Attribution-Noncommercial-No Derivative Works 4.0 License.

\section{Citation/Publisher Attribution \\ McCurdy, K., Daro, D., Anisfeld, E., Katzev, A., Keim, A., LeCroy, C., McAfee, C.,...Winje, C. (2006). Understanding maternal intentions to engage in home visiting programs. Children and Youth Services Review, 28(10), 1195-1212. doi: 10.1016/j.childyouth.2005.11.010 Available at: https://doi.org/10.1016/j.childyouth.2005.11.010}

This Article is brought to you for free and open access by the Human Development and Family Science at DigitalCommons@URI. It has been accepted for inclusion in Human Development and Family Science Faculty Publications by an authorized administrator of DigitalCommons@URI. For more information, please contact digitalcommons-group@uri.edu. 


\section{Authors}

Karen McCurdy, Deborah Daro, Elizabeth Anisfeld, Aphra Katzev, Ann Keim, Craig LeCroy, Courtney McAfee, Carnot Nelson, Lydia Falconnier, William M. McGuigan, Jennifer K. Park, James Sandy, and Carolyn Winje 


\title{
Understanding maternal intentions to engage in home visiting programs
}

\author{
Karen McCurdy ${ }^{a},{ }^{*}$, Deborah Darob ${ }^{b}$ Elizabeth Anisfeld ${ }^{c}$, Aphra Katzevd ${ }^{d}$ Ann Keim ${ }^{\mathrm{e}}$, Craig \\ LeCroy $^{f}$, Courtney McAfee $^{g}$, Carnot Nelson ${ }^{h}$, Lydia Falconnieri, William M. McGuiganj, \\ Jennifer K. Park ${ }^{\mathrm{e}}$, James Sandy ${ }^{\mathrm{C}}$, and Carolyn Winje ${ }^{\mathrm{b}}$ \\ aHuman Development and Family Studies, University of Rhode Island, 2 Lower College Road, \\ Kingston, RI 02881 USA \\ bUniversity of Chicago, Chicago, IL, USA \\ cColumbia University, New York, NY, USA \\ dOregon State University, Corvallis, OR, USA \\ eUniversity of Wisconsin - Madison, Madison, WI, USA \\ fUniversity of Arizona, Tuscon, AZ, USA \\ gGeorgia Council on Child Abuse, Atlanta, GA, USA \\ hUniversity of South Florida, Tampa, FL, USA \\ iUniversity of Illinois - Chicago, Chicago, IL, USA \\ jPennsylvania State University, Sharon, PA, USA
}

\section{Abstract}

Little is known as to why some parents choose to engage in voluntary home visitation services while others refuse or avoid services. To address this knowledge gap, this study tests several hypotheses about the factors that influence maternal intentions to engage in home visitation services and the link between these intentions and the receipt of a home visit. The sample consists of an ethnically diverse group of mothers identified as at-risk for parenting difficulties $(N=343)$. These mothers were offered home visitation services from nine home visiting programs located across six states. Regardless of service acceptance or refusal, all mothers were interviewed within 2 weeks of the service offer and 3 months later.

The findings suggest that mothers who intend to use services look substantially different from those who do not state an intention to participate in home visitation. The results indicate that lower infant birth weight and greater comfort with a provider in one's home are significant predictors of maternal intentions to utilize home visiting services. The study results also support the connection between intent and behavior as the expressed intention to engage in home visitation services was a key predictor of the receipt of a visit.

\section{Keywords}

Home visitation; Prevention; At-risk mothers; Intentions; Parental behavior

\author{
(C) 2005 Elsevier Ltd. All rights reserved \\ *Corresponding author. Tel.: +1 401874 5960; fax: +1 401874 4020. E-mail address: kmccurdy @ uri.edu (K. McCurdy).
}




\section{Introduction}

Family-focused, home visitation programs have shown some promise as a way to improve maternal and child health (McCurdy, 2000) and reduce negative parenting behaviors and attitudes (Daro \& Harding, 1999). Research in the field, however, continues to note low retention and high attrition rates among eligible families, factors believed to reduce service effectiveness (Gomby, Culross, \& Behrman, 1999). It seems that many families fail to take full advantage of the services offered to them despite the relative ease of service participation. In acknowledgement of this threat to program validity, social scientists have begun to explore whether certain participant, provider or neighborhood characteristics differentiate those who remain in home visitation programs from those who drop out (Daro, McCurdy, Falconnier, \& Stojanovic, 2003; McCurdy, Gannon, \& Daro, 2003; McGuigan, Katzev, \& Pratt, 2003).

In contrast, limited scholarly attention has focused on a critical and related issue - the problem of recruiting target families into services (McCurdy \& Daro, 2001; Wagner, Spiker, Linn, Gerlach-Downie, \& Hernandez, 2003). Studies of home visiting programs have documented that significant portions of eligible families never receive a visit. Many families refuse service offers outright, what we call "active" refusals. Studies suggest active refusals reduce the number of participants by $8 \%$ (Marcenko \& Spence, 1994) to 20\% (Center on Child Abuse Prevention Research, 1996; Liaw \& Brooks-Gunn, 1994; Seigel, Bauman, Schaefer, Saunders, \& Ingram, 1980). In addition, families sometimes agree to enroll in services but are never available for a visit, what we call "passive" refusals. The size of the passive refusal population, however, is harder to estimate. Studies calculating the number of passive refusals ranged from a low of $12 \%$ to $14 \%$ (Duggan et al., 1999; Katzev, Pratt, \& McGuigan, 2001), to a high of $22 \%$ (Wagner et al., 2003). However, the typical published home visitation study does not report this statistic (e.g., Culp, Culp, Blankemeyer, \& Passmark, 1998; Navaie-Waliser et al., 2000).

The dearth of information regarding families who avoid services has led to some debate over the reasons for non-participation with at least two competing explanations receiving support. On the one hand, a family's service avoidance may reflect the accurate belief that they already have adequate parenting support or do not need these specific services. A study by Duggan et al. (2000) supports this hypothesis as families who actively refused home visitation services had higher educational levels and healthier infants than those who accepted services. The refusal of home visiting services might then indicate an informed consumer choice rather than a failure on the part of the program or provider. On the other hand, a family's service refusal may reflect a tendency toward isolation or a higher level of risk for parenting difficulties. Research by Nicholson, Brenner, and Fox (1999), indicating that young maternal age, low educational attainment, and lower child expectations predicted a greater likelihood of dropping out of services, supports the latter explanation. If true, this reason creates a quandary as families believed to be at risk for child abuse are often the target audience for home visitation programs.

The current study was designed explicitly to address this gap in the knowledge base. Drawing on a theory of engagement and retention (see McCurdy \& Daro, 2001), the goal of this prospective study is to determine what characteristics distinguish parents who either actively or passively avoid services from those who participate in at least one home visit. By testing specific hypotheses about maternal intentions to participate in home visitation services, we hope to advance the empirical evidence that can be used to design more effective recruitment strategies and services.

\subsection{Theoretical framework}

McCurdy and Daro (2001) have proposed a parent involvement theory that recognizes the influence of factors located at multiple ecological levels (i.e., parent, provider, program) on 
parental decisions to engage in home visitation (see Fig. 1). Earlier work in the fields of health promotion (Ajzen, 1996; Fishbein \& Ajzen, 1975) and student retention (Bean, 1982) illustrates the importance of intentions for explaining future behavior. This earlier research demonstrates that the strongest predictor of a person engaging in a specific behavior, say participating in a home visiting program, is the person's stated intention to do so (Fishbein et al., 1997). Thus, parents who state that they intend to use home visiting services will be more likely to receive a visit than those who voice no intention to utilize services. Given this link between intent and behavior, assessing the factors that influence intentions becomes the initial component in examining the engagement process. The primary aim of the current research is to examine the following series of hypotheses regarding factors that influence a parent's intent to enroll in home visiting services:

$\mathbf{H}_{\mathbf{1}}$ (Perceived need for services). Parents who perceive a need for services, either due to their own risk or the risk of their child, are hypothesized to be more likely to intend to use services (see Duggan et al., 2000; Luker \& Chalmers, 1990).

$\mathbf{H}_{2}$ (Program costs vs. benefits). Parents who perceive greater benefits than costs from participating in home visits will demonstrate a higher probability to intend to participate (see Gatchel \& Baum, 1983).

$\mathbf{H}_{3}$ (Readiness to change). Parents expressing greater readiness to change their parenting will be more likely to intend to receive visits than parents with lower readiness levels (see McConnaughy, DiClemente, Prochaska, \& Velicer, 1989; Prochaska \& DeClemente, 1984).

$\mathbf{H}_{\mathbf{4}}$ (Subjective norms about network support). The likelihood of intending to participate will be higher for parents who perceive their friends and family as supportive of home visitation programs than parents holding more negative perceptions of their network's subjective norms (see Luker \& Chalmers, 1990).

$\mathbf{H}_{5}$ (Service delivery style). Participants will be more likely to express an intent to enroll if the service recruiter possesses an empathetic and competent service delivery style.

$\mathbf{H}_{\mathbf{6}}$ (Timing of enrollment). Mothers offered services during pregnancy will demonstrate a greater likelihood of intending to use services than mothers offered services around the child's birth (see Weiss, 1993).

Our second aim is to test the hypothesis that stated intentions to participate in home visitation will be the strongest predictor of enrollment (defined here as receipt of a home visit), but not the sole determinant of enrollment. Reflecting that the second critical point in the engagement process is the actual receipt of a visit, the study explores which variables predict enrollment and whether these variables differ from the variables presumed to influence intentions.

\section{Method}

This study addresses the engagement component of a comprehensive study on engagement and retention in home visiting programs with data collected from programs, providers and participants at nine sites utilizing the Healthy Families America (HFA) home visitation framework. The HFA framework consists of two processes: 1) an early identification (EID) system used to recruit new or expecting parents who may be at risk for parenting problems; and 2) a community-based, non-medical home visitation program that offers intensive visits to parents identified as "at-risk" through the EID system. HFA seeks to enroll new parents as early as possible into services and to retain parents for the first 5 years of the child's life or until the child enters an educational setting such as preschool. 


\subsection{HFA home visitation program}

HFA is a national effort that offers intensive home visitation services in over 300 rural, urban, and suburban communities across 35 states. While a few HFA programs operate statewide, most programs target services to parents of newborns or pregnant mothers living in a specific community or geographic catchment area. Depending on the program's structure, assessment and recruitment of mothers into services may occur during pregnancy, within 2 weeks of the newborn's birth, or at both time points. HFA staff works with clinic and hospital personnel to identify all mothers of newborns in a catchment area. If a brief review of the mother's medical information indicates a possible need for parenting assistance (e.g., did not obtain prenatal care, has no telephone, teenage mother), a more intensive assessment is initiated with the family.

The second assessment, a structured interview, is conducted by a trained family assessment worker (FAW) with the pregnant or new mother, and father, if available, either at the hospital, clinic or home. The FAWs utilize the Kempe Family Stress Inventory (KFSI; Murphy, Orkow, $\&$ Nicola, 1985) to assess ten factors related to parental dysfunction including negative perceptions of the child, parental depression, and isolation. As research indicates that KFSI scores of 25 or more by either parent correspond to risk for inadequate parenting behavior (Murphy et al., 1985), such scores elicit an offer of HFA home visitation services to the family. At this point, parents can either accept or refuse services. If the family accepts service, a trained Family Support Worker (FSW) attempts to initiate a home visit within 2 weeks of the child's birth or 2 weeks after prenatal enrollment. Families who decline HFA services or are screened out at any point in this process receive a list of available community support services (e.g., doctors, parent support groups, WIC, etc.).

Once a parent accepts services, HFA programs offer the following common elements: 1) intensive (i.e., weekly) visits by FSWs during the 1st year; 2) the creation of an family service plan based on identified parent and child needs; 3 ) the connection of each family to a medical "home"; 4) a curriculum designed to enhance child development knowledge and nurturing parent-child interactions at each visit; and 5) the provision of necessary referral or advocacy services for the parent (e.g., housing) or child (e.g., health screening).

\subsection{Site and sample selection}

A purposeful sample of nine home visiting programs was drawn primarily from a group of 17 programs with prior involvement in a pilot, retrospective study of retention (see Daro et al., 2003). All 17 programs were invited to participate in a follow-up, prospective study of engagement and retention with the goal of securing ten programs representing diverse geographic regions of the United States. Five of the original 17 programs agreed to participate along with three programs closely affiliated with the earlier study programs. These eight programs provided home visiting services to communities in the following five states: Arizona, Florida, Georgia, New York, and Oregon. To expand geographic diversity, a ninth program located in Wisconsin was invited to participate and accepted. This ninth program has been credentialed by HFA as its structure and design adheres to the core elements of the HFA framework (A. Keim, personal communication, March, 2002).

Enrollment into the study occurred between January 2001 and March 2002. Each program enrolled consecutive parents until a minimum of 30 families had agreed to study participation. Of the 430 families eligible for HFA services and study enrollment, $349(81 \%)$ agreed to participate and provided informed consent. The current sample further excludes 6 cases involving families experiencing infant death, loss of custody or parental imprisonment for a final sample of 343 families. On average, 38 parents (range $=31$ to 43 ) participated at each program. 


\subsection{Procedures}

When enrolling families in services, Family Assessment Workers (FAWs) asked all eligible parents if they would be interested in participating in a study examining the reasons parents decide to use or not use home visiting services. If the parent responded yes, an initial contact form was completed providing the parent's name, address, phone number and similar information about one contact person. Parental consent was required for eligible teens living in states with such requirements. If the parent responded no to the study offer, research staff made no further attempt to contact the parent. Study acceptance did not affect the receipt of home visitation services. If the parent expressed interest in the study, the FAW forwarded the initial contact form to research staff. A trained researcher at each program then contacted the parent to explain the study, answer any questions, and arrange the first interview with interested parents. Informed consent was obtained prior to the start of the first interview by the researchers, and at the start of any subsequent interviews. The informed consent forms and study protocols were approved by the Institutional Review Board of the University of Chicago.

Initial participant interviews took place within 2 weeks of completing the HFA enrollment process. Participants were paid $\$ 25$ for the interview. The majority of initial interviews lasted 60 to $90 \mathrm{~min}$. The study team also collected service data from the provider and program.

\subsection{Measures}

Data for the following analyses come primarily from responses to the initial participant interview questionnaire though information regarding enrollment status (e.g., receipt of one or more visits) is drawn from the provider data for some participants. To accurately estimate measure reliabilities, all available participant data were used $(n=349)$, including data from parents $(n=6)$ excluded from the current analyses due to subsequent ineligibility to receive services (e.g., loss of child custody, death of child).

2.4.1. Dependent variables-To measure a parent's intent to enroll in services, all participants were asked the question "Do you plan to use the services?" with "yes" coded as 1 $(n=326)$, and "no or not sure" coded as $0(n=17)$. The second outcome, enrollment, is coded as 1 "one or more visit" $(n=306)$ or 0 "no visits" $(n=37)$. The final outcome variable, engagement, is coded as 0 "Active avoider" ( $n=17), 1$ "Passive avoider" $(n=26)$, and 2 "Visited" $(n=300)$. The 6 subjects who expressed no intent to use services but received a visit are included in the active avoider group as they did not continue in the program.

2.4.2. Perceived need for service-Home visitation research has identified parental perceptions of infant risk (Olds \& Kitzman, 1993), and beliefs about parental need for services (Luker \& Chalmers, 1990) as potential determinants of service participation. To assess maternal perceptions of infant risk, mothers of newborns were asked to give the following information: infant birth weight, gestational age, whether the infant was placed in special nursery at birth (yes or no), infant availability for post-birth physical contact with mother (yes or no), and overall infant health (excellent, good, fair, or poor).

To assess maternal assumptions about service necessity, all participants were asked whether twelve specific aspects of parenting and access to support concerned them. These aspects included concerns they may have for their infant (e.g., concerns about feeding your baby?), their personal life (e.g., concerns about paying your bills), and their relationships (e.g., concerns about your relationship with your partner/spouse). The responses to these twelve items were combined into a total concerns index with acceptable internal reliability $(\alpha=.70)$.

2.4.3. Cost of HFA involvement-As other responsibilities (Gomby et al., 1999; McNaughton, 2000) may take precedence over home visits, measures of current and future 
availability were administered (Gross, Julion, \& Fogg, 2001). Current availability was assessed in three areas: 1) current school enrollment (yes or no); 2) current work status (employed or not employed); and 3) current participation in another parent or child program (yes or no). As a measure of future availability, participants were asked whether they planned on moving in the next 6 months (Gomby et al., 1999). A final potential cost is the experience of discomfort with a service delivery process that occurs in the home (Slaughter-Defoe, 1993). To assess this cost, participants were asked to rate their comfort with a home visitor on a 5-point Likert scale ranging from very uncomfortable (1) to very comfortable (5).

2.4.4. Benefits of HFA involvement-Potential benefits of the program were assessed in three ways. Research by Powell (1984) and Birkel and Repucci (1983) implies that parents with more limited networks will perceive greater benefits from program involvement. To measure network support, participants were asked a series of questions about their ability to obtain needed help in six areas (e.g., child care, material goods, transportation) from the partner or father of the baby (FOB), family or close relatives, friends or neighbors, and organizations or service agencies. A total network support index was created $(\alpha=.71)$, with lower scores indicating more limited support.

The second benefit construct, need for community integration, relied on a set of single items to examine whether the parent appeared to be relatively isolated in her personal or parenting career. Participants were asked whether they were a first-time mother, the length of time lived in the neighborhood (with new defined as less than 12 months), whether they lived alone, and whether they knew of alternative support programs.

The perception of program helpfulness was the third benefit assessed. Participants were asked to use a 4-point scale ( $1=$ no help; $4=$ lot of help) to rate the program's overall helpfulness to the following individuals or groups: 1) participant; 2) baby; 3) partner/FOB; and 4) entire family. A response of "don't know" was coded as 1 "no help" because the participant could not identify any potential utility of the program. To maximize data, the three items measuring helpfulness to the participant, baby and entire family were combined to create the $H F A$

helpfulness index. This index achieved a high reliability, $\alpha=.72$, with no loss of data $(n=343)$ as compared to an index of all four items, including helpfulness to partner/FOB $(\alpha=.67, n=$ $308)$.

2.4.5. Readiness to change parenting-To assess a participant's readiness to change her parenting, we adapted the University of Rhode Island Change Assessment Scale (URICA) Stages of Change Long Form (Prochaska \& DiClemente, 1983). This measure consists of 32 Likert items spread across four successive scales: pre-contemplation, contemplation, action and maintenance. According to McConnaughy et al. (1989), high precontemplation scores characterize individuals not seeking to change their behavior; high contemplation scores indicate individuals who have acknowledged a problem exists; high action scores describes individuals taking concrete steps to address the identified problem; and high maintenance scores indicate sustained progress. Research confirms that individuals can be reliably clustered into these stages (McConnaughy et al., 1989) and that individuals at higher stages of change (e.g., action) tend to be more responsive to interventions than individuals at lower levels (e.g., precontemplation; Prochaska and DiClemente). This study utilizes six items from the action scale $(\alpha=.71)$, with the word "parenting" substituted for the word "problem".

2.4.6. Subjective norms about network support—Subjective norms, or a person's perceptions of other's support (Fishbein \& Ajzen, 1975), are hypothesized to influence both intent to enroll in home visiting services and the actual receipt of a visit (Luker \& Chalmers, 1990). Participants were asked to rate the perceived comfort level of their network members with a home visitor on 5 -point Likert scale $(1=$ very uncomfortable to $5=$ very comfortable $)$ 
and their perceptions of network support for HFA involvement on a similar scale $(1=$ very much against to $5=$ very much for). Ratings were obtained for partner/father of baby (FOB), when applicable, parents, friends, and relatives. A participant response of "don't know" was assigned a neutral rating of 3 (neither for nor against; neither comfortable nor uncomfortable). Factor analysis of the eight items supported the construction of two separate norm indices: a partner norm index including the two partner/FOB items $(\alpha=.83)$; and a network norm index including the 6 items assessing parent, friends, and relative norms $(\alpha=.77)$.

2.4.7. Service delivery style-Participants rated the service delivery style of the Family Assessment Worker (FAW) with items drawn from the Helping Relationship Inventory (HRI, Young \& Poulin, 1998). The HRI was designed to examine both structural and interpersonal components of the client-social worker relationship with a 20 -item measure completed separately by the client and provider. As the brief contact between the FAW and participant does not lead to a structural relationship between the two, an interpersonal scale was created by selecting nine items that examine participant beliefs about the provider such as "Do you feel you two are alike in some ways?" Responses ranged from $1=$ not at all, to $5=$ a great deal. Cronbach's $\alpha$ of .92 indicated high internal consistency in this sample.

2.4.8. Timing of enrollment-As noted earlier, timing of enrollment into services varied across the nine HFA programs. Four programs recruited all participants after birth. The five remaining programs enrolled both pregnant and post-partum women. Prenatal enrollment, a dichotomous variable, was defined as 1 "pregnant at service offer" or 0 "gave birth by service offer."

\subsection{Participant characteristics}

Overall, the sample was ethnically diverse with $32 \%$ African-American, $33 \%$ white, $25 \%$ Hispanic/Latina, and $9 \%$ from other or mixed ethnic groups. The participants displayed a demographic profile that may place them at risk for future parenting. The typical mother was relatively young $($ mean $=23.0$, S.D. $=5.2)$, unmarried $(84.5 \%)$ yet living with at least one other adult (86\%), and without a high school degree (48\%). Only 35\% were either in school or were working at the start of the study. The majority of participants (71\%) were giving birth for the first time and $30 \%$ were pregnant at the time of study enrollment.

At the time of study entry, 238 participants (69\%) had recently given birth to the target child. Some of these infants were at risk for developmental delays. About $19 \%$ were born prematurely (less than 37 weeks), $13 \%$ had low birth weights $(<2500 \mathrm{~g})$, and $16 \%$ were placed in a special nursery (e.g., NICU) immediately after birth. By comparison, $12 \%$ of U.S. infants were born prematurely and $7.8 \%$ had low birth weights in 2002 (Hamilton, Martin, \& Sutton, 2003).

\subsection{Analyses}

First, we tested the hypotheses regarding intent to enroll using $\chi^{2}$ analysis and $t$-tests by comparing those voicing an intention to use HFA services to those without a stated intention. Variables achieving a significance level of .05 were then subjected to a correlational analysis with any highly correlated items $(r>.40)$ inspected for elimination from the exploratory logistic regression. Due to small sample size $(n=17)$ in the no intent group, the full theory could not be tested with multivariate analysis. Instead, logistic regression with backwards elimination was conducted to explore the relative influence of the constructs. These procedures were repeated with the next dependent variable, enrollment, defined as receipt of a visit. Finally, a series of univariate analyses of variance equations and Kruskal-Wallis non-parametric equations were calculated to explore whether predictors of intent differed from predictors of enrollment using the third outcome variable, engagement. 


\section{Results}

\subsection{Intent to use HFA services}

Table 1 presents all significant demographic and predictor variables that distinguish the intending from the non-intending participants. Minority status emerged as significant with selfidentified minorities representing a significantly larger portion of those intending to use services than non-intending parents $(p<.05)$. In terms of perceived need for service, perceptions of infant risk and need for services both influenced intent to enroll. First, maternal reports of infant birth weight revealed that infants born to parents intending to use HFA were significantly lighter than infants born to parents not planning on using HFA $(p<.001)$. Second, intending mothers noted twice the number of concerns for one's self, child and/or other relationships $(p<.001)$ as non-intending parents.

The cost associated with having a visitor come to one's home emerged as a highly significant factor in this sample. Participants who intended to enroll reported significantly more comfort with a home visitor than participants expressing no intent to use HFA $(p<.001)$. Other potential costs, such as school enrollment, current work, attending another parenting program, or planning to move in the near future, did not affect intentions to use home visiting services.

The evidence around perceived program benefits was mixed. The findings contradicted our hypothesis that more isolated parents would be more likely to intend to use services. Participants intending to enroll reported significantly more total support available $(p<.05)$ than non-intending parents. Also contrary to our expectations, first-time mothers represented a significantly smaller portion of the intending group than the non-intending group $(p<.05)$. As expected, scores on the HFA helpfulness index demonstrated that intending parents perceived HFA as significantly more helpful to themselves, their child and their family as a whole than did their non-intending counterparts $(p<.001)$.

Readiness to change, subjective norms, and FAW service delivery style differentiated those with no intent to enroll from those intending to enroll. The intending group posted significantly higher readiness to change scores $(p=.01)$, were more likely to perceive both their partner $(p<.05)$ and their immediate network $(p<.05)$ as supportive or comfortable with HFA, and gave their FAW higher ratings on the interpersonal scale $(p<.01)$ than parents expressing no intention to receive visits. Prenatal enrollment did not significantly influence intentions although a trend $(p<.10)$ was apparent with prenatal access corresponding to a greater likelihood to intend to enroll.

As might be expected given the number of tests run and the reliance on maternal self-report for these data, a number of variables achieved statistically significant correlations. For example, the two subjective norm indices were moderately correlated $(r=.29, p<.001)$. The data also revealed a moderate correlation between the two subjective norm indices with the participant's own comfort level with a home visitor ( $r$ values >.33), suggesting that perceptions of other's norms are associated with one's own belief system. As no correlations reached 40 , all indices and variables were available for multivariate analyses.

Next, backwards logistical regression analysis was conducted with all significant predictor variables and minority status. Model 1 , shown in Table 2, identifies the four most influential variables from this set. In terms of perceived need for service, every one-unit increase in the total concerns index results in a $52 \%$ increase in the odds of intending to use services. High costs and low benefits of home visitation also influenced intentions. A one-unit increase in comfort with the home visitor corresponded to a $259 \%$ increase in the likelihood of intending to use services. Further, a one-unit increase in ratings of HFA helpfulness led to an $82 \%$ increase in the odds of intending to use services. Measures of participant readiness to change, subjective 
norms and provider attributes fell out of these models. Minorities, however, were 3.9 times more likely to intend to enroll than non-minorities.

Model 2, also shown in Table 2, presents the results for the 238 mothers who had given birth at the time they were approached for home visiting services. The findings suggest that infant birth weight impacts intentions for this group. For every one pound increase in birth weight, a parent was 58\% less likely to intend to receive a visit $(p<.01)$. An increase in the other three predictors, total concern index, participant comfort with the home visitor, and the HFA helpfulness index, significantly increased the odds that post-partum mothers intended to use services. Minority status, however, was not significant for post-partum participants.

\subsection{Enrollment (receipt of a visit)}

Table 3 displays the significant $(p<.05)$ differences between parents who received a home visit $(n=306)$ and parents who did not $(n=37)$. Two parental attributes differentiated the groups. First, participants who identified themselves as a member of a minority group were significantly more likely to receive a visit than white, non-Hispanic participants $(p<.05)$. Second, participants living with an adult relative other than a parent or partner were more likely to receive a visit than participants living without this type of relative $(p<.05)$. As with enrollment, infant birth weight influenced visits. Mothers of children with lower birth weights were more likely to receive at least one visit than mothers of heavier infants $(p<.05)$. Other indicators of service necessity were not significant.

The cost of service involvement as measured by future availability proved significant for enrollment decisions. Parents who planned on moving in the next 6 months were significantly less likely to receive a visit than parents without such plans $(p<.05)$. Other costs, such as comfort with a home visitor, did not differentiate visited from non-visited mothers. In terms of potential benefits from home visitation, network size and need for community integration produced no significant effects on enrollment decisions. The perceived benefits of home visiting, however, influenced enrollment as parents receiving at least one visit gave significantly higher ratings on the HFA helpfulness index than parents without a visit $(p<.05)$.

Measures of parental readiness to change, perceptions of partner and network subjective norms, and provider service delivery style failed to differentiate visited from non-visited parents. Timing of enrollment, however, was significant. About one-third of the visited group was enrolled prenatally as compared to only $11 \%$ of the non-visited group $(p<.05)$. As expected, intent to enroll was highly and positively correlated with enrollment $(p<.001)$. Close to $100 \%$ of visited parents stated that they intended to use home visiting services as compared to only $74 \%$ of non-visited parents. Due to the limited variation on this variable, it was excluded from the following multivariate analyses.

Table 4 presents the final results of the exploratory logistic regression analyses predicting visits with backward entry of the significant predictor variables. For all participants (Model 1), three variables emerged as significant. Mothers living with another adult relative were 3.2 times more likely to receive a visit $(p<.05)$ than those with a different living arrangement. The belief one might move in the next 6 months reduced the likelihood of receiving a visit by $56 \%$ ( $p<$. $05)$. The most significant variable was timing of enrollment as parents offered services prenatally were about 5 times more likely to receive a visit than those offered services after birth $(p=.01)$. Additionally, a trend emerged such that a one-unit increase in the HFA helpfulness index led to a $20 \%$ increase in the likelihood of a visit $(p<.07)$.

When limiting the analyses to those participants who had given birth (Model 2), infant birth weight was the most significant predictor with every $1 \mathrm{lb}$ increase in birth weight decreasing 
the odds of receiving a visit by $28 \%(p<.05)$. No other variable emerged as significant for this subgroup.

\subsection{Engagement}

Univariate ANOVAs and Kruskal-Wallis equations were calculated to test whether different factors predicted membership in three distinct groups: visited mothers $(n=300)$, passive avoiders (i.e., expressed an intention to receive visits, $n=26$ ), and active avoiders (i.e., those with no expressed intention to receive home visits, $n=17$ ). To determine which groups differed significantly, post hoc comparisons are reported. Table 5 presents the results and demonstrates that, with a few exceptions, active avoiders were significantly different from both of the comparison groups.

Reflecting a limited need for services, the active avoiders gave birth to the heaviest infants and expressed the fewest parenting concerns as compared to both the passive avoider and visited groups. Parents not intending to use services expressed significantly less comfort with a home visitor and lower perceptions of HFA helpfulness than passive avoiders and visited mothers $(p<.001)$. Unexpectedly, active avoiders were significantly more likely to be first-time mothers than the comparison groups $(p<.05)$. Finally, such mothers stood out in terms of subjective norms as they perceived their partners as less accepting of both the program and visitor than passive avoiders or visited mothers $(p<.05)$.

In some areas, significant differences were apparent only between the active avoiders and the visited mothers. For example, minorities represented a significantly higher proportion of the visited group than the active avoider group $(p<.05)$. In terms of readiness for parenting change, active avoiders received significantly lower scores on the action scale of the URICA $(p<.05)$ than visited mothers, with passive avoiders falling in the middle. A similar finding was apparent with maternal perceptions of recruiter service delivery style. Active avoiders gave significantly lower ratings of interpersonal compatibility with the FAW than did visited mothers $(p<.01)$ and passive avoiders fell in between.

Two significant differences emerged between the passive avoiders and their visited counterparts. Mothers who intended to use HFA but never received a visit were more likely to report planning to move in 6 months $(p<.05)$ and were less likely to have been recruited prenatally as compared to mothers who received at least one visit $(p<.01)$.

\section{Discussion}

The study results help illuminate several characteristics that shape initial service engagement patterns. While a relatively small group, mothers who do not express an intention to use home visiting services looked substantially different from their counterparts who declare an intention to use services. In contrast, fewer differences could be discerned between mothers who intended to use services but never received a visit, and mothers who participated in at least one home visit. These results support the hypothesis that identifying predictors of intention is a critical first step to understanding initial engagement patterns (Bean, 1982).

The study found some evidence supporting the first hypothesis that maternal perceptions of service necessity influence intentions to participate in home visiting. For mothers who had given birth prior to enrollment, lower birth weight was a robust predictor of engagement. It should be noted that giving birth to an infant whose weight met the medical criteria for low birth weight $(<2500 \mathrm{~g})$ was NOT the key determinant of engagement. These findings suggest that new mothers are keen infant observers and responsive to any perceived infant risk such as lower birth weight and/or shorter gestational age (McGuigan et al., 2003). Home visiting programs will most likely find such mothers a receptive target for recruitment efforts. In 
contrast, mothers who do not perceive specific risks for their infant may represent a more reluctant group in need of other persuasions related to their own life or relationship concerns.

Other measures of service necessity revealed similar results. In accordance with the literature (Lukers \& Chalmers, 1990; McNaughton, 2000), active avoiders of HFA services clearly articulate a lesser need for home visitation than their intending counterparts. Further, such mothers express fewer concerns about many aspects of their life, including raising their child. While these findings corroborate the prediction that parents who do not perceive themselves as being "at risk" are less likely to engage in home visiting services, other results raise some questions about why this pattern occurs. Unexpectedly, active avoiders also reported significantly fewer available support sources than mothers who intended to use services, a finding which contradicts Herzog, Cherniss, and Menzel's (1986) study of high risk adolescents. Taken together, these results could lead to the interpretation that mothers who avoid HFA home visiting services outright either need less help with parenting or are less comfortable receiving help.

However, a third interpretation may exist. Because the active avoider group consists primarily of first-time mothers (94\%), it is possible that some of these new parents hold a "naïve" perspective relative to parenting. Some first-time parents may be less open to service offers because they do not possess a great deal of knowledge regarding the challenges of child rearing and therefore see no evidence of personal risk or need. Two recent studies provide support for further investigation of the naïve perspective. Pratt and her colleagues surveyed 307 first-time mothers within 7 days of birth and 6 months later. At 6 months, a retrospective assessment of the mothers' post-partum parenting situation demonstrated that the first-time mothers had overestimated their parenting skills and ability to access support at the time of the child's birth (Pratt, McGuigan, \& Katzev, 2000). Another study by Myors, Johnson, and Langdon (2001) concluded that limited knowledge of parenting allowed pregnant adolescents to employ optimistic coping mechanisms that downplayed future child-rearing challenges. If the naïve perspective is true, recruiters may need more intensive recruitment efforts to address these overly optimistic beliefs of first-time mothers. Programs also might want to consider additional recruitment efforts for this group, such as attempting a visit 3 to 6 months after the child's birth.

As predicted in our second hypothesis, the participants in this sample appear to engage in a process of weighing the potential costs and benefits of service involvement. Mothers perceiving fewer costs and higher benefits of HFA were more likely to intend to use services and to receive a visit. In terms of costs, the focal point appeared to be the in-home visits rather than lack of time due to conflicting responsibilities. Parents expressing lower comfort levels with a visitor tended to avoid services, and tended to perceive their network as less comfortable with a home visitor. These findings support the proposition that home visiting is not attractive to some segments of the target population (Slaughter-Defoe, 1993). While studies have examined the relative efficacy of different types of parenting programs, little is known about the relative appeal of center versus home-based service delivery methods. Research comparing rates of engagement for families offered home visitation versus families offered center-based services would help bridge this knowledge gap. Such research could potentially identify characteristics of families interested in center-based as opposed to home-based services, as well as distinguish those parents with no interest in any service modality.

Cost alone, however, did not fully explain service decisions. Perceived benefits for the parent, child and family also emerged as a significant predictor of engagement. Intenders possess a more coherent vision of how home visiting potentially can help their families than nonintenders. To find out why this discrepancy occurs, programs should systematically assess how recruiters describe program benefits and how parents understand this description. Recruitment 
efforts that offer all things to all parents may result in large enrollments but suffer from greater attrition down the road as parents realize that the perceived benefit is not going to materialize. Parents who misinterpret benefits or identify unlikely benefits, such as one parent who described the opportunity to attend Lamaze classes as a program benefit, may be disappointed by actual services. Careful assessment may overcome this problem and result in a service delivery plan more closely aligned with parental needs and expectations, a key ingredient for a collaborative client-provider relationship (Josten et al., 2002; McNaughton, 2000).

The bivariate analyses supported the hypotheses that readiness to change parenting (H3), subjective norms about network support (H4), and recruiter service delivery style (H5) influenced participant behavior in the predicted manner. That is, mothers who received a visit evidenced the highest readiness to change their parenting, viewed their network as supportive of home visiting services, and gave high ratings to the HFA service recruiter on interpersonal compatibility. However, the exploratory multivariate analyses suggest that perceived need for service and cost/benefits assumptions might be more crucial predictors of parental behavior. While these findings are tentative, future research may want to utilize a more parsimonious model to examine engagement patterns.

Adding to the ongoing debate over timing of service enrollment (Daro et al., 2003; Gomby, Larson, Lewit, \& Behrman, 1993), the study findings did not support the hypothesis that prenatal recruitment would increase the likelihood of intending to use services. The findings, however, did suggest that prenatal recruitment increased the likelihood that mothers received at least one visit. As studies to date have not identified any negative impacts of prenatal recruitment, the bulk of research appears to support the practice of offering service before birth as a successful strategy to engage parents more fully in home visiting services.

Unexpectedly, minority status proved significantly related to engagement behavior, with nonHispanic whites representing a greater portion of the non-intending families. Other home visitation studies also report an impact of race/ethnicity on retention rates (McCurdy et al., 2003; McGuigan et al., 2003; Wagner et al., 2003) though with mixed results. Future research needs to carefully analyze this construct and include measures of socioeconomic status to begin to partial out the true effects of race/ethnicity.

\subsection{Study limitations}

A major study limitation was the small percent of participants (11\%) who did not receive a home visit. While this limitation represents a great achievement for the HFA programs, it restricted our ability to examine engagement with rigorous multivariate techniques. Future studies of engagement will need to cast a wider net to gain a sufficient number of people who refuse services outright as well as those who do not intend to use services.

Because the study relied on self-report data from eligible HFA participants, the moderate to high correlations found among a number of variables may only reflect similarity in the methods used to collect the data. As these correlations may result in either the understating or overstating of effects, caution is needed when interpreting the data. Another constraint concerns the study population as the results noted here may not apply to participants in other home visiting programs or parenting services.

\subsection{Conclusions}

Despite these limitations, the research greatly expands our knowledge of maternal intentions to use home visitation services, with implications for practice and research. From a practice standpoint, the findings underscore the role social desirability appears to play in the service recruitment process. Only seven people refused service offers outright. When asked whether 
mothers intended to use services, a larger number gave negative or neutral responses, suggesting a greater degree of candidness either with the wording of this question or with the non-program interviewer. If programs want to better recognize likely non-engagers, gathering information on intentions using more covert methods might be a critical first step. For example, the recruiter might ask the parent how often she would like a home visitor to come visit or how long she would want services to last to estimate the parent's receptivity to services.

The findings also indicate that programs need to find methods to reach those parents who are somewhat receptive to services yet fail to participate in at least one visit. In this study, parents planning on moving soon were most likely to belong to this group. Providers need to think about how to make home visiting services more attractive to potentially transient populations. Offers to help connect the family with similar services at any future location and an emphasis on some immediate benefits that will be provided by the home visitor (e.g., diapers, infant health evaluations, infant feeding tips) might be some potential ways to entice this group into active participation.

From a research perspective, the finding that maternal intentions clearly distinguish two different types of non-visited families raises important considerations in conducting future research on service engagement. First, combining all parents who fail to receive a service into one non-visited comparison group most likely will obscure important differences among these non-engagers, potentially leading to findings with limited utility for policy makers or researchers. More importantly, parental behavior toward intervention programs clearly follows from parental intentions. If we wish to better understand and potentially influence parental behavior, future research needs to continue investigating the factors that govern maternal intentions using multi-dimensional theoretical frameworks.

\section{Acknowledgments}

This study was supported by grants from the William T. Grant Foundation and the Annie E. Casey Foundation. An earlier version of this paper was presented at the 2004 Annual Conference for the National Conference on Family Relations.

\section{References}

Ajzen, I. The directive influence of attitudes on behavior. In: Gollwitzer, P.; Bargh, J., editors. The psychology of action. New York: Guilford Press; 1996. p. 385-403.

Bean, J. Conceptual models of student attrition: How theory can help the institutional researcher. In: Pascarella, E., editor. Studying student attrition. San Francisco: Jossey-Bass Inc.; 1982. p. 17-33.

Birkel R, Repucci ND. Social networks, information-seeking, and the utilization of services. American Journal of Community Psychology 1983;11:185-205. [PubMed: 6869325]

Center on Child Abuse Prevention Research. Intensive home visitation: A randomized trial, follow-up and risk assessment study of Hawaii's Healthy Start program (NCCAN Grant No. 90-CA-1511). Chicago: National Committee to Prevent Child Abuse; 1996.

Culp A, Culp R, Blankemeyer M, Passmark L. Parent education home visitation program: Adolescent and nonadolescent mother comparison after six months of intervention. Infant Mental Health Journal 1998;19(2):111-123. [PubMed: 12294463]

Daro D, Harding K. Healthy families America: Using research in going to scale. The Future of Children 1999;9(1):152-176. [PubMed: 10414015]

Daro D, McCurdy K, Falconnier L, Stojanovic D. Sustaining new parents in home visitation services: Key participant and program factors. Child Abuse and Neglect 2003;27:1101-1125. [PubMed: 14602094]

Duggan A, McFarlane E, Windham A, Rohde C, Salkever DS, Fuddy L, et al. Evaluation of Hawaii's healthy start program. The Future of Children 1999;9(1):66-99. [PubMed: 10414011] 
Duggan A, Windham A, McFarlane E, Fuddy L, Rohde C, Buckbinder S, et al. Hawaii's Healthy Start program of home visiting for at-risk families: Evaluation of family identification, family engagement, and service delivery. Pediatrics 2000;105(1):250-259. [PubMed: 10617732]

Fishbein, M.; Ajzen, I. Belief, attitude, intention and behavior: An introduction to theory. Reading, MA: Addison-Wesley; 1975.

Fishbein, M.; Guenther-Gray, C.; Johnson, W.; Wolitski, R.; McAlister, A.; Rietmeijer, C. Using a theorybased community intervention to reduce AIDS risk behaviors: The CDC's AIDS community demonstration projects. In: Goldberg, M.; Fishbein, M.; Middlestadt, S., et al., editors. Social marketing: Theory and practical perspectives. Mahwah, NJ: Lawrence Erlbaum; 1997. p. 123-146.

Gatchel, R.; Baum, A. An introduction to health psychology. Reading, MA: Addison-Wesley; 1983.

Gomby D, Culross P, Behrman R. Home visiting: Recent program evaluations - analysis and recommendations. The Future of Children 1999;9(1):4-26. [PubMed: 10414008]

Gomby D, Larson C, Lewit E, Behrman R. Home visiting: Recent program evaluations - analysis and recommendations. The Future of Children 1993;3(6):22.

Gross D, Julion W, Fogg L. What motivates participation and dropout among low-income urban families of color in a prevention intervention? Family Relations 2001;50(3):246-255.

Hamilton, B.; Martin, J.; Sutton, P. National vital statistics reports. Vol. vol. 51. Hyattsville, MD: National Center for Health Statistics; 2003. Births: Preliminary data for 2002; p. 1-20.

Herzog EP, Cherniss DS, Menzel BJ. Issues in engaging high-risk adolescent mothers in supportive work. Infant Mental Health Journal 1986;7:59-68.

Josten L, Savik K, Anderson M, Benedetto L, Chabot C, Gifford M, et al. Dropping out of maternal and child home visits. Public Health Nursing 2002;19(1):3-10. [PubMed: 11841677]

Katzev, A.; Pratt, C.; McGuigan, W. Oregon healthy start 1999 - 2000 status report. Corvallis, OR: Oregon State University; 2001.

Liaw F, Brooks-Gunn J. Cumulative familial risks and low-birthweight children's cognitive and behavioral development. Journal of Clinical Child Psychology 1994;23(4):360-372.

Luker KA, Chalmers KI. Gaining access to clients: The case of health visiting. Journal of Advanced Nursing 1990;15:74-82. [PubMed: 2303617]

Marcenko M, Spence M. Home visitation services for at-risk pregnant and postpartum women: A randomized trial. American Journal of Orthopsychiatry 1994;64(3):468-478. [PubMed: 7977669]

McConnaughy E, DiClemente C, Prochaska J, Velicer W. Stages of change in psychotherapy: A followup report. Psychotherapy 1989;26(4):494-503.

McCurdy, K. What works in child abuse prevention programs: Healthy families America. In: Kluger, M.; Alexander, G.; Curtis, P., editors. What works in child welfare. Washington, DC: CWLA Press; 2000. p. 45-55.

McCurdy K, Daro D. Parent involvement in family support programs: An integrated theory. Family Relations 2001;50(2):113-121.

McCurdy K, Gannon R, Daro D. Participation in home-based, family support programs: Ethnic variations. Family Relations 2003;52(1):3-11.

McGuigan W, Katzev A, Pratt C. Multi-level determinants of retention in a home-visiting child abuse prevention program. Child Abuse and Neglect 2003;27:363-380. [PubMed: 12686322]

McNaughton D. A synthesis of qualitative home visiting research. Public Health Nursing 2000;17(6): 405-414. [PubMed: 11115138]

Murphy S, Orkow B, Nicola R. Prenatal prediction of child abuse and neglect: A prospective study. Child Abuse and Neglect 1985;9:225-235. [PubMed: 4005663]

Myors K, Johnson M, Langdon R. Coping styles of pregnant adolescents. Public Health Nursing 2001;18 (1):24-32. [PubMed: 11251870]

Navaie-Waliser M, Martin SL, Campbell MK, Tessaro I, Kotelchuck M, Cross AW. Factors predicting completion of a home visitation program by high-risk pregnant women: The North Carolina maternal outreach worker program. American Journal of Public Health 2000;90:121-124. [PubMed: 10630150]

Nicholson B, Brenner V, Fox R. A community-based parenting program with low-income mothers of young children. Families in Society: The Journal of Contemporary Human Services 1999:247-254. 
Olds D, Kitzman H. Review of research on home visiting for pregnant women and parents of young children. The Future of Children 1993;3(3):53-92.

Powell D. Social network and demographic predictors of length of participation in a parent education program. Journal of Community Psychology 1984;12:13-20.

Pratt C, McGuigan W, Katzev A. Measuring program outcomes: Using retrospective pretest methodology. American Journal of Evaluation 2000;21(3):341-350.

Prochaska, J.; DiClemente, C. The transtheoretical approach: Crossing traditional boundaries of therapy. Homewood, IL: Dow Jones/Irwin; 1984.

Seigel E, Bauman K, Schaefer E, Saunders M, Ingram D. Hospital and home support during infancy: Impact on maternal attachment, child abuse and neglect, and health care utilization. Pediatrics 1980;66:183-190. [PubMed: 7402803]

Slaughter-Defoe D. Home visiting with families in poverty: Introducing the concept of culture. The Future of Children 1993;3(3):172-183.

Wagner M, Spiker D, Linn MI, Gerlach-Downie S, Hernandez F. Dimensions of parental engagement in home visiting programs: Exploratory study. Topics in Early Childhood Special Education 2003;23 (4):171-187.

Weiss H. Home visits: Necessary but not sufficient. The Future of Children 1993;3(3):113-128.

Young T, Poulin J. The helping relationship inventory: A clinical appraisal. Families in Society: The Journal of Contemporary Human Services 1998 March - April;79:123-133. 


\section{Maternal perceptions of self and program}

- Perceived service need

- Infant risk

- Maternal risk

- Cost-benefit assessments

- Readiness to change parenting

- Subjective norms about network support

Maternal perceptions of recruiter

- Service delivery style

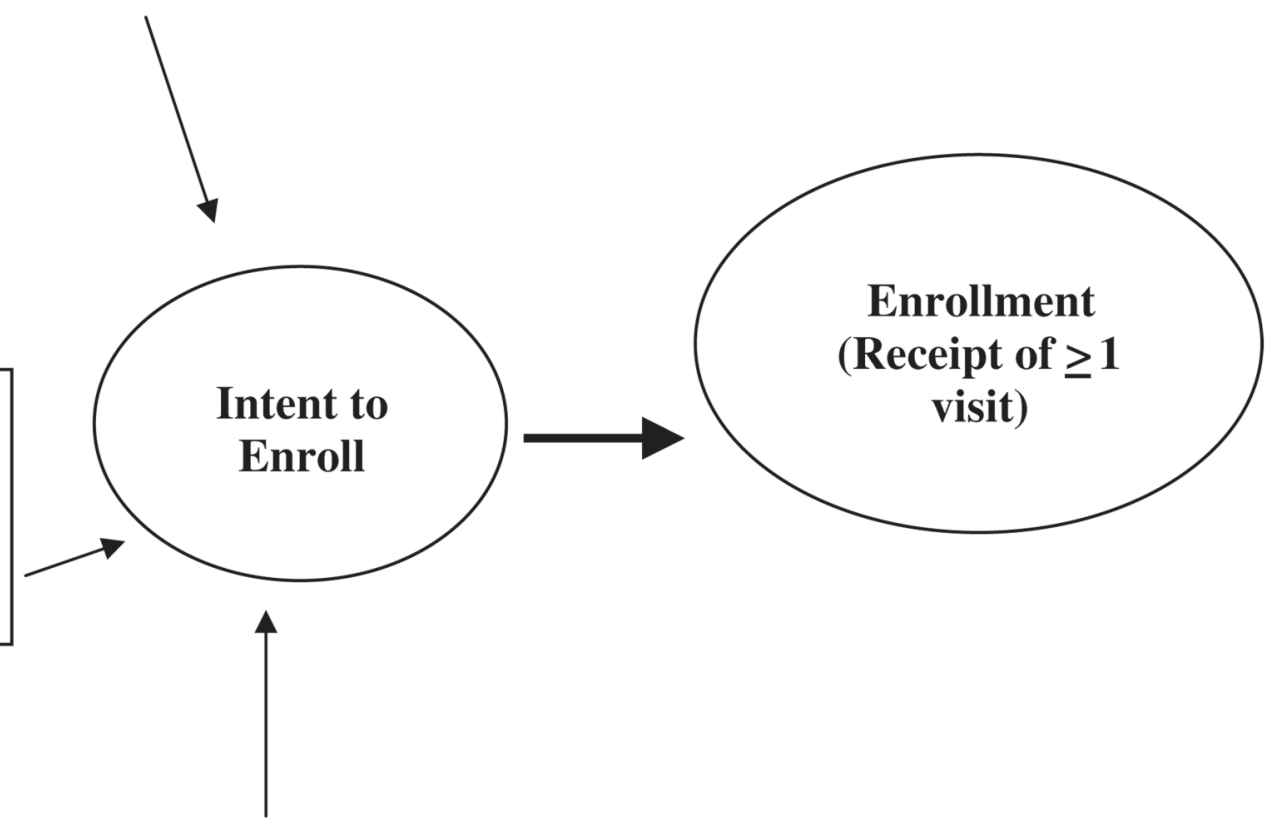

\section{Service availability}

- Timing of enrollment

- Pre or post-natal

Fig. 1.

Factors hypothesized to predict intent to enroll and enrollment in home visiting programs. 
Table 1

Significant predictors of intent to enroll

\begin{tabular}{|c|c|c|c|}
\hline Variables & No intent $(n=17)$ & Intent $(n=326)$ & Statistic $t$ or $\chi^{2}$ \\
\hline \multicolumn{4}{|l|}{ Demographic attributes } \\
\hline$\%$ Minority status & $41.2(7)$ & $68.7(224)$ & $4.389^{*}$ \\
\hline \multicolumn{4}{|l|}{ Perceived need for services } \\
\hline$M$ Infant birth weight & $8.1(1.6)$ & $6.8(1.4)$ & $-3.4^{* * *}$ \\
\hline$M$ Total concerns index & $2.2(2.3)$ & $4.4(2.6)$ & $3.4^{* * *}$ \\
\hline \multicolumn{4}{|l|}{ Cost/benefit items } \\
\hline$M$ Comfort with home visitor & $3.0(0.9)$ & $3.9(0.8)$ & $4.7^{* * * *}$ \\
\hline$M$ Total support available index & $7.7(4.2)$ & $10.2(4.3)$ & $2.4^{*}$ \\
\hline$\%$ First-time mother & $94.1(16)$ & $69.9(228)$ & $4.6^{*}$ \\
\hline$M$ HFA helpfulness index & $7.7(2.0)$ & $10.4(1.7)$ & $6.7^{* * *}$ \\
\hline \multicolumn{4}{|l|}{ Readiness to change } \\
\hline$M$ Action & $3.6(0.6)$ & $4.0(0.5)$ & $2.6^{* *}$ \\
\hline \multicolumn{4}{|l|}{ Subjective norms } \\
\hline$M$ Partner norms & $5.9(1.4)$ & $6.9(1.6)$ & $2.5^{*}$ \\
\hline$M$ Network norms & $19.1(2.8)$ & $21.3(4.1)$ & $2.3^{*}$ \\
\hline \multicolumn{4}{|l|}{ Service delivery style } \\
\hline$M$ Interpersonal scale & $2.7(1.0)$ & $3.5(1.0)$ & $3.0^{* *}$ \\
\hline \multicolumn{4}{|l|}{$M=$ mean } \\
\hline \multicolumn{4}{|l|}{${ }^{*} p<.05$} \\
\hline $\begin{array}{l}* * \\
\quad p<.01\end{array}$ & & & \\
\hline$* * * * .001$ & & & \\
\hline
\end{tabular}


Table 2

Exploratory logistic regression analyses predicting intends to enroll

\begin{tabular}{lrrrr}
\hline Variable & Coefficient (S.E.) & Wald & Odds ratio & $p$ \\
\hline Model 1 - All participants & & & & \\
Total concerns index & $42(0.16)$ & 7.0 & 1.52 & .008 \\
Comfort with home visitor & $1.27(0.42)$ & 9.4 & 3.59 & .002 \\
HFA helpfulness index & $60(0.16)$ & 13.7 & 1.82 & .000 \\
Minority status & $1.37(0.63)$ & 4.7 & 3.94 & .029 \\
Constant & $-8.98(2.1)$ & 18.3 & 0.000 & .000 \\
Model 2 - Post-partum participants & & & & \\
Total concerns index & $0.38(0.19)$ & 4.0 & 1.46 & .045 \\
Comfort with home visitor & $0.99(0.42)$ & 4.5 & 2.70 & .033 \\
HFA helpfulness index & $0.59(0.20)$ & 8.6 & 1.80 & .003 \\
Infant birth weight (lb) & $-0.86(0.29)$ & 9.0 & 0.42 & .003 \\
Constant & $-0.88(2.70)$ & 0.1 & 0.42 & .744 \\
\hline
\end{tabular}

Model 1: $\chi^{2}(4340)=55.52, p<.001,-2$ Log Likelihood $=79.5$. Model 2: $\chi^{2}(4238)=49.5, p<.001 ;-2$ Log Likelihood $=62.51$. 
Table 3

Significant predictors of enrollment using $t$-tests and $\chi^{2}$ analyses

\begin{tabular}{|c|c|c|c|}
\hline Variables & No visits $(n=37)$ & Visited $(n=306)$ & $t$ or $\chi^{2}$ \\
\hline \multicolumn{4}{|l|}{ Demographic attributes } \\
\hline$\%$ Minority status & $51.4(19)$ & $69.3(212)$ & $4.83^{*}$ \\
\hline$\%$ Lives with other adult relative & $10.8(4)$ & $28.4(87)$ & $5.30^{*}$ \\
\hline \multicolumn{4}{|l|}{ Perceived need for services } \\
\hline$M$ Infant birth weight $(n=239)$ & $7.4(1.3)$ & $6.8(1.4)$ & $2.07^{*}$ \\
\hline \multicolumn{4}{|l|}{ Potential costs/benefits of HFA } \\
\hline$\%$ Moving in 6 months & $61.1(22)$ & $42.9(130)$ & $4.31^{*}$ \\
\hline$M$ HFA helpfulness index & $9.6(2.2)$ & $10.4(1.7)$ & $-2.02^{*}$ \\
\hline$\%$ Prenatal enrollment & $10.8(4)$ & $32.7(100)$ & $6.47^{*}$ \\
\hline$\%$ Intends to enroll & $74.3(26)$ & $98.0(300)$ & $54.00^{* * *}$ \\
\hline \multicolumn{4}{|l|}{$M=$ mean.} \\
\hline \multicolumn{4}{|l|}{${ }^{*} p<.05$} \\
\hline$\stackrel{* * *}{p} p<.001$. & & & \\
\hline
\end{tabular}


Table 4

Exploratory logistic regression analysis predicting enrollment

\begin{tabular}{|c|c|c|c|c|}
\hline Variable & Coefficient (S.E.) & Wald & Odds ratio & $\boldsymbol{P}$ \\
\hline \multicolumn{5}{|l|}{ Model 1 - All participants } \\
\hline Lives with another adult relative & $1.15(0.55)$ & 4.32 & 3.16 & .038 \\
\hline Moving in 6 months & $-0.77(0.37)$ & 4.25 & 0.46 & .039 \\
\hline HFA helpfulness index & $0.18(0.10)$ & 3.48 & 1.20 & .062 \\
\hline Prenatal enrollment & $1.61(0.62)$ & 6.70 & 4.99 & .010 \\
\hline Constant & $1.37(1.1)$ & 1.63 & 3.95 & .20 \\
\hline \multicolumn{5}{|l|}{ Model 2 - Post-partum participants } \\
\hline Lives with another adult relative & $1.07(0.56)$ & 3.59 & 2.91 & .058 \\
\hline Moving in 6 months & $-0.73(0.39)$ & 3.52 & 0.48 & .061 \\
\hline Infant birth weight (lb) & $-0.33(0.16)$ & 4.46 & 0.72 & .035 \\
\hline Constant & $5.42(1.3)$ & 17.17 & 226.7 & .000 \\
\hline
\end{tabular}

Model 1: $\chi^{2}(4339)=24.36, p<.001,-2$ Log Likelihood $=205.14$. Model $2: \chi^{2}(3238)=13.14, p=.004,-2$ Log likelihood $=178.47$. 


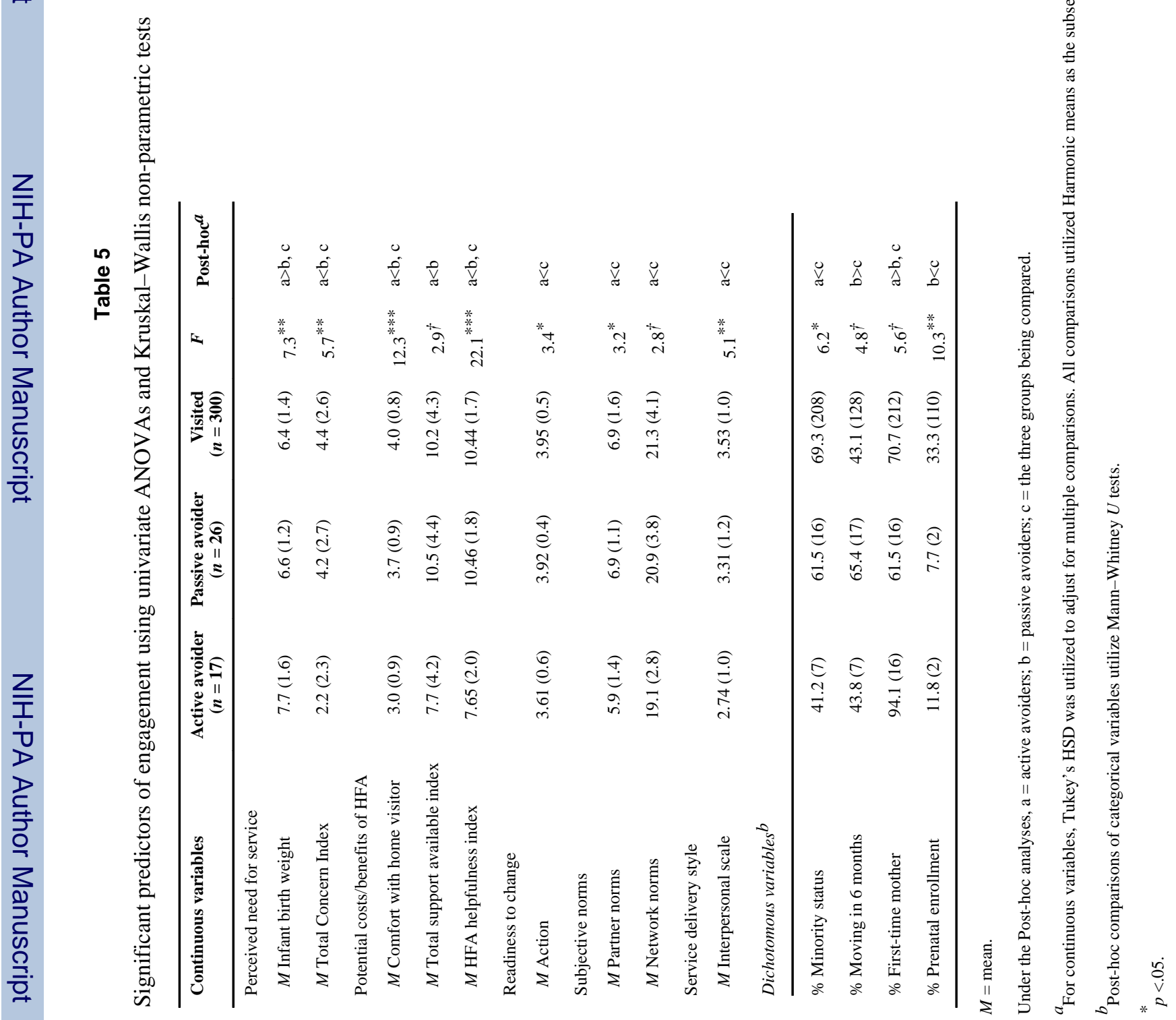


